like UP, that is showing signs of emerging epidemic. These emerging districts and sub-epidemics are related to population migration, and lack of focus on preventive measures. Kanpur is one of the industrial centers of UP with considerable migrant population. The low awareness regarding HIV transmission noted in the study $(0-5.6 \%)^{1}$ among road-side barbers is of special concern and may point to lack of focus on IEC and other preventive strategies in this geographical area. It is important to bring this to the notice of the state AIDS Control Organization and NACO.

Though the results of the study may not be of major concern with regard to HIV epidemic in India, it has implications on other blood borne infections. There is greater need for effective strategies to control transmission of HBV and HCV in the community. Vaccination and ensuring improved hygienic practices are the best answers to this problem. I am sure that the information generated in the article will help us to refocus our efforts in strengthening the strategies to control blood borne infections in the country.
R E F E R E N C E S

1. Nath B, Kumari R, Midha T, Vaswani ND, Lekhwani S. Profession of barbering: unexplored issues in HIV/AIDS. CEGH. 2013;1.

2. Von Reyn CF, Mann JM, Chin J. International travel and HIV infection. WHO Bull. 1990;68:251-259.

3. Batham A, Narula D, Toteja T, Sreenivas V, Puliyel JM. Systematic review and meta-analysis of prevalence of hepatitis B in India. Indian Pediatr. 2007;44:664-674.

4. Kurien T, Thyagarajan SP, Jeyaseelan L, et al, STD Study Group. Community prevalence of hepatitis B virus infection and modes of transmission in Tamil Nadu, India. Indian J Med Res. 2005;121:670-675.

5. National AIDS Control Organization, Ministry of Health \& Family Welfare, Government of India. State Fact Sheet (Internet) 2012; March 2012. Available from: http://www.nacoonline.org/ NACO/Quick_Links/Publication/State_Fact_Sheets/.

6. Arni SR, Kurien T, Sudhakar K, Philip KM. HIV/AIDS epidemic in India and predicting the impact of the national response: mathematical modeling and analysis. Math Biosci Eng. 2009;6:779-813.

\title{
IndiaClen recommendations for improving postgraduate medical research \& publication
}

IndiaClen 2013 Annual Conference Group (ACG), Jyotsna Agarwal ${ }^{a}$, Madhuri Kulkarni ${ }^{b}$, Uday Mohan ${ }^{c}$, Vinita Das ${ }^{d}$, Vinita Singh ${ }^{e}$, Siddharth Das ${ }^{f}$, Pankaj Bhardwaj ${ }^{g}$, Pragna Rao ${ }^{h, i}$, Sanjay Mehendale ${ }^{j}$, Vimala Venkatesh ${ }^{a}$, Archana Kumar ${ }^{k}$, Nandini Kumar ${ }^{l}$, Nuzhat Hussain ${ }^{m}$, Pankaja Ravi Raghav ${ }^{n}$, Ranabir Pal ${ }^{\circ}$, Apul Goel ${ }^{p}$, Rashmi Kumar ${ }^{q}$, Farzana Beg ${ }^{r}$, Ashraf Malik ${ }^{s}$, Raj Mohan Pillai ${ }^{\mathrm{t}}$, Vinod Paul ${ }^{u}$, Sushil Kumar Kabra ${ }^{v}$, Ravindra Mohan Pandey ${ }^{w}$, L. Jeyseelan ${ }^{x}$, Suresh Ughade ${ }^{y}$, Prathap Tharyan ${ }^{z}$, Jai Veer Singh ${ }^{a a}$, Raj Mehrotra ${ }^{b b, c c}$, V.N. Tripathi ${ }^{\text {dd }}$, Neeraj Mohan Srivastava ${ }^{e e}$, Priya Tripathi ${ }^{f f}$, Akansha $^{99}$, Arpita ${ }^{9 g}$, Tavishi Srivastava ${ }^{9 g}, J^{9 h n v i}{ }^{9 g}$, Raj Gaurav Singh ${ }^{g 9}$, Sarika Gupta ${ }^{\text {hh }}$, Aditya Vidyasagar ${ }^{\text {ii }}$, S. Chakraborty jij, Shally Awasthi ${ }^{k k, l l, *}$

\footnotetext{
a Professor, Department of Microbiology, KGMU, Lucknow, India

${ }^{\mathrm{b}}$ Professor, Department of Pediatrics, LTM Medical College and Hospital, Mumbai, India

${ }^{\mathrm{c}}$ Professor, Department of Community Medicine, KGMU, Lucknow, India

${ }^{\mathrm{d}}$ Professor \& Head, Department of Obstetrics \& Gynecology, KGMU, Lucknow, India

e Professor \& Head, Department of Ophthalmology, KGMU Lucknow, India

${ }^{\mathrm{f}}$ Professor \& Head, Department of Rheumatology, KGMU Lucknow, India

${ }^{g}$ Assistant Professor, Community Medicine \& Family Medicine, AIIMS, Jodhpur, India

${ }^{\mathrm{h}}$ Professor \& Head, Department of Bio-Chemistry, Kasturba Medical College, Manipal, India
}

\footnotetext{
* Corresponding author.

E-mail address: Shally07@gmail.com (S. Awasthi).
} 
${ }^{\mathrm{i}}$ Director of PG studies, Kasturba Medical College, Manipal, India

${ }^{j}$ Director, National Institute of Epidemiology, Chennai, India

${ }^{\mathrm{k}}$ Professor, Department of Pediatrics, KGMU, Lucknow, India

${ }^{1}$ Former Deputy Director General, Sr. Grade, ICMR, India

${ }^{\mathrm{m}}$ Dean Medicine, RMLIMS, Gomti Nagar, Lucknow, India

${ }^{\mathrm{n}}$ Professor, Department of Community Medicine \& Family Medicine, AIIMS, Jodhpur, India

${ }^{\circ}$ Additional Professor, Department of Community Medicine, AIIMS, Jodhpur, India

p Professor, Department of Urology, KGMU, Lucknow, India

${ }^{\mathrm{q}}$ Professor \& Head, Department of Pediatrics, KGMU, Lucknow, India

${ }^{\mathrm{r}}$ Reader, Department of Pediatrics, AMU, Aligarh, India

${ }^{\mathrm{s}}$ Professor of Pediatrics, Principal, JNMC, Aligarh, India

${ }^{\mathrm{t}}$ Secretary - IndiaCLEN Director, CEU, Medical College, Trivadrum, India

u Professor \& Head, Department of Pediatrics, AIIMS, New Delhi, India

v Professor, Department of Pediatrics, AIIMS, New Delhi, India

${ }^{w}$ Professor \& Head, Department of Biostatistics, AIIMS, New Delhi, India

${ }^{x}$ Professor, Department of Bio-Statistics, CMC Hospital, Vellore, India

${ }^{y}$ Professor, Department of Community Medicine, Government Medical college, Nagpur, India

${ }^{\mathrm{z}}$ Director, South Asian Cochrane Network \& Centre, CMC, Vellore, India

${ }^{\text {aa }}$ Professor \& Head, Department of Community Medicine, KGMU, Lucknow, India

${ }^{\mathrm{bb}}$ Head, Department of Pathology, KGMU, Lucknow, India

${ }^{\mathrm{cc}}$ Dean, Faculty of Medicine, KGMU, Lucknow, India

dd Principal and Dean, Government Medical college, Ambedkar Nagar, UP, India

${ }^{\text {ee }}$ Knowledge Manager, Health Department, UNICEF, India

${ }^{\mathrm{ff}}$ Department of Genetics, SGPGIMS, Lucknow, India

gg Junior Residents, Department of Pediatrics, KGMU, Lucknow, India

${ }^{\mathrm{hh}}$ Senior Resident, Department of Pediatrics, KGMU, Lucknow, India

${ }^{\text {ii }}$ CEO, Vidyasagar Associates, India

${ }^{\mathrm{jj}}$ Former Dean, IIM, Lucknow, India

${ }^{\mathrm{kk}}$ President, IndiaClen, India

${ }^{11}$ Professor, Department of Pediatrics, King George Medical University, Lucknow, India

\section{Background}

There are approximately 22,000 postgraduate (PG) seats and 35,000 undergraduate (UG) seats in India. PGs seats are for degree as well as diploma courses. There are many more seats for degree courses than diploma courses and majority of the seats are governed by the Medical Council of India (MCI) system and about $20 \%$ by the National Board of Examination (NBE). Two-thirds of the MCI seats are in the government institutions, whereas more than four-fifths of the NBE seats are in private institutions. By and large those who do not qualify for the MCI seats enroll in the parallel Diploma of the NBE. As a pre-requisite of the MCI and NBE systems, the PGs conduct original research work under a faculty guide/mentor and submit is as thesis/dissertation prior to appearing for the examination. Questions are asked as to what does this research work mean for the PG student, what is its added value, and on a more radical front, why is it done? It has been cited that $85 \%$ of all research work done is wasteful or inefficient, ${ }^{1}$ with deficiencies in the relevance of research question for clinicians or patients of local area or not addressing the local needs, inappropriate design and methods, inaccessibility of the full report, and issues about the work being unbiased and clinically meaningful. ${ }^{1}$ The situation in India with reference to PG research work is similar. Lessons learned early result in behavior changes and inculcate set practice patterns. Hence probably generations of medical PGs have graduated into clinicians, academicians and researchers who give insufficient attention to details and depths of problems. This may be one main reason why Indian research is not globally acclaimed.

Recently there are national funding opportunities. Our PGs must have the appropriate skills to answer clinical questions pertaining to health and diseases of India. This is the time to "restructure and reframe the way research is done and rewarded"2 in India. Therefore, IndiaClen, in its annual conference held on 2-3 March 2013 in King George's Medical University deliberated on the theme "Improving PG Medical Research and Publications in India”.

\section{Methodology}

The recommendations were developed during brain storming sessions which took place during the 2-day Annual IndiaClen conference held on 2-3 March 2013, in King George's Medical College, Lucknow. There were background lectures by eminent academicians and researchers followed by two brain storming sessions of $2 \mathrm{~h}$ each. In each brain storming session, about 20-30 faculty and PG students made two groups and discussed the issues on how to improve PG research. The ideas were collated within the group, exchanged with the other group and then final set of recommendations were drafted. The participants of the brain storming sessions had attended the lectures given earlier in the day. The sessions had two moderators, external to medical profession and in the field of management and two faculty facilitators of discussions. 


\section{Results}

\subsection{Consensus opinion}

Majority felt that PG research is needed and it should not be done away with or made optional because exposure to research techniques and acquisition of research skills make medical doctors better clinicians. Current system of PG research leading to submission of thesis for the final examination however needs improvement. Lack of time, lack of research mind-set of both guide and student and lack of funds to conduct research were the main lacunae that were identified during discussions and deliberated upon. It was agreed that there was a need to critically think about the need and scope for reforms in postgraduate research to make it more meaningful.

\section{Recommended proposal to resolve deficiencies}

\subsection{PG teachers/guides}

- Capacity building of postgraduate teachers is necessary. To become a postgraduate teacher eligible to guide a postgraduate MD student, the faculty should complete "Research Methodology" course and earn credit units.

- Postgraduate teachers should participate in mandatory refresher courses, periodically [Continuous Research Hours] to retain their registration as postgraduate teachers.

- Specific credentials need be considered for recognizing the faculty as PG teachers or guides.

- Some form of "Recognition" of the faculty that is involved in research work needs to be considered.

- Opportunities for research sabbatical in renowned institutions in India and abroad should be created and postgraduate teachers with good records should be encouraged to participate in such exchange programs.

\subsection{Medical colleges/Institutions/Universities}

- Medical colleges/Institutions/Universities should make a commitment to foster research by employing dedicated full time faculty, preparing institutional SOPs, providing budget for postgraduate research and providing administrative support in the form of Dean/Vice Dean for Research.

- Protect time for research for faculty and PG Students with measurable outputs.

- Dedicated PG Research Cells should be established in each institute to facilitate thesis/research and publication. This cell can be mandated to organize "Design Specific Protocol Workshops" (general) for all PGs within 6 months of joining PG. It should be mandatory for the PGs to participate in these and get themselves certified before formally registering for the postgraduate degree at the university. Additional customized workshops can be held to finalize study protocols. A competent biostatistician should be a member of PG Cell.

- After submission of the theses, another workshop for PGs on "Scientific Communication" should be held to facilitate paper writing and participation in this should also be mandatory for PGs.
- Research Oversight Cell should be established to overview the quality of research and address issues related to scientific misconduct.

- There is a need to develop and implement a comprehensive training module on 'Ethics and Regulations' for the postgraduates.

- Guidelines should be laid down for authorship claims for publications resulting from medical postgraduate research/ theses.

- Institutional Review Board or Ethics Committees [IRB/EC] should be made functional and active and should be immediately registered as per the revised norms of CDSCO. Institutions should make special efforts to provide training to IRB/EC members in protocol review, ethical conduct of biomedical research and concerned regulatory issues.

- It is important to ensure proper maintenance of Hospital Data Records to assist PGs during their research work.

- The libraries should be provided additional budget for wider electronic access to important key journals.

\subsection{Better engagement of PG students in postgraduate research}

- Widely acclaimed researchers at the institutional/national level should have greater interaction with new PG entrant to motivate or encourage them.

- "Career Counseling" should be arranged for PG students to apprise them of the importance of research.

- There is a need to provide well-designed technical training on "Research Methodology" followed by "Biostatistics" in PG curriculum early during residency,

- For improvement of soft skills, PGs should have an access to specially designed courses, such as "Communication skills", protocol writing and manuscript.

- Since practical experience was important, short-term studies of not more than 3-6 months [eg. process improvement for clinical/lab research and/or effective patient care] should be available for the postgraduate students.

- To encourage capacity building and personality development, a short thesis, one publication and an oral presentation could be recommended as key deliverables of the PG program. Submission of literature review on the topic of interest should be mandatory for PG students within first three months. The possibility of giving objective weightage to thesis work by allotting marks should be considered.

- Periodic review of PG thesis work should be done by Departmental committee/External experts. Processes for validation of data collected and reported by the PGs should be in place.

- "Journal Clubs" with critical appraisal of published research articles should be conducted for capacity building of PGs.

- Travel incentives to present PG research work at conferences at national and international levels should be provided. Similarly, other types of "Recognition" for PG students conducting good research work should be considered.

\subsection{Improving research publications}

- Good thesis can always lead to a good publication. Hence PG research planning, design and execution as well as thesis 
writing should be improved. This will prepare a good background for potentially good publication. Hence training of PG guides is critical to improve the quality research and resulting high quality publications.

- Publications should be encouraged but not made compulsory before appearing for postgraduate examination.

- Role of Alumni in improving research can also be explored at the institutional level.

\section{Acknowledgments}

This conference was partially co-sponsored by the Indian Council for Medical Research and the Medical Council of India. Prof. D.K. Gupta, Vice Chancellor, KGMU provided access to institutional infrastructure for the conference.

R E F E R E N C E S

1. Chalmers I, Glasziou P. Viewpoint. Lancet. 2009;374:86-89.

2. Editorial What is the purpose of medical research?. Lancet. 2013;381(9864):347.

\section{Annual India CLEN Conference, 2nd and 3rd March 2013}

King's George Medical University, Lucknow, Uttar Pradesh, India

The study of prevalence and associated risk factors for hypertension among adult ( $>20$ years) rural population of RTHC, Kalyanpur

Sunil Kumar, C. Roy, V. Roy

$\mathrm{DMCH}$, Darbhanga, India

Background: Cardiovascular disease especially hypertension is a major public health problem in both developed and developing countries and can lead to heart attacks, strokes and cardiac and renal failure. Common risk factors for hypertension include age, sex, genetic factor, ethnicity, lifestyle modification, stress and strain, socio-economic status. Most of projected rise in hypertension is preventable.

Objective: (1) To study the prevalence of hypertension among rural adult ( $>20$ years) population of RTHC, Kalyanpur, (2) To know the associated risk factors of hypertension among rural adult population.

Setting/Method:

Study Area: Field practice area of Darbhanga Medical College i.e. Rural Training Health Centre, Kalyanpur.

Study Design: This is a community based cross-sectional study.

Study Subjects: Both male and female adults aged 20 years and above.

Study Period: The study was conducted from April 2011 to April 2012.

The author underlined is the Presenting author.
Sample Size: The sample size required for the study was 1,160. Allowing $5 \%$ sample loss, the total sample size was calculated to be 1,210 .

Results: Out of 1210 participants 217 (17.9\%) were found hypertensive. Of the total 217 subjects higher prevalence rate was observed in females $(21.08 \%)$ as compared with males (15.27\%). Vegetarian had a lesser prevalence of hypertension than those with non-vegetarian ( $p>0.5)$. Alcoholics had a higher prevalence of hypertension than non alcoholics and was found to be highly significant $(\mathrm{p}<0.001)$. Proportion of Diabetics who were hypertensive was $33.83 \%$. Multiple logistic regression analysis of risk factor of hypertension showed alcohol, smoking, tobacco, diabetes, tobacco chewing and BMI to be significantly associated with risk factor of developing hypertension.

Conclusion: Prevalence rate of $17.9 \%$ found in this study is consistent with overall increasing trend of hypertension both in India (Rural and Urban) and worldwide. This could be attributed to increase in aging population, changing life style and change in diagnostic criteria over the years.

\section{Measuring the burden of tuberculosis in India: What data are needed?}

\section{Krycia Cowling, R. Dandona, L. Dandona}

Public Health Foundation of India, New Delhi, India

Background: Despite having the greatest tuberculosis burden of any country, estimates of tuberculosis incidence, 